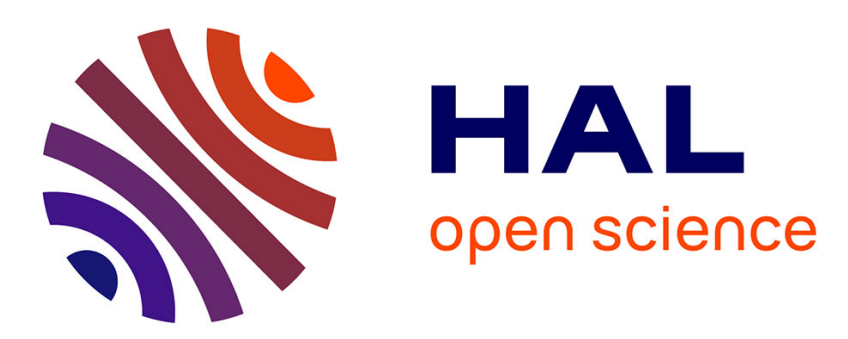

\title{
Design of Technology and Technology of Design. Activity Analysis as a Resource for a Personalised Approach for Patients with Parkinson Disease
}

Elodie Lalo, J. Riff, R. Parry, M. Jabloun, J. Roussel, C.-C. Chen, M.-L.

Welter, Olivier Buttelli

\section{To cite this version:}

Elodie Lalo, J. Riff, R. Parry, M. Jabloun, J. Roussel, et al.. Design of Technology and Technology of Design. Activity Analysis as a Resource for a Personalised Approach for Patients with Parkinson Disease. Innovation and Research in BioMedical engineering, 2016, 10.1016/j.irbm.2016.02.010 . hal01298677

\section{HAL Id: hal-01298677 https://hal.sorbonne-universite.fr/hal-01298677}

Submitted on 6 Apr 2016

HAL is a multi-disciplinary open access archive for the deposit and dissemination of scientific research documents, whether they are published or not. The documents may come from teaching and research institutions in France or abroad, or from public or private research centers.
L'archive ouverte pluridisciplinaire HAL, est destinée au dépôt et à la diffusion de documents scientifiques de niveau recherche, publiés ou non, émanant des établissements d'enseignement et de recherche français ou étrangers, des laboratoires publics ou privés. 


\section{Design of technology and technology of design.}

Activity analysis as a resource for a personalized approach for patients with Parkinson disease

Elodie Lalo ${ }^{1,3}$, Jacques Riff ${ }^{3}$, Ross Parry ${ }^{1}$, Meryem Jabloun ${ }^{2}$, Julien Roussel ${ }^{2}$, Chiung-Chu Chen $^{5}$, Marie-Laure Welter ${ }^{1,4}$ Olivier Buttelli ${ }^{2}$

\section{Abstract}

Using a personalized medicine perspective, ECOTECH aims at developing new tools and methodologies to characterize and overcome at-risk situations for patients with Parkinson's disease in their daily life activity. With the cooperation of a multidisciplinary research group, patient situations have been studied in real life context in both hospital environment and home and community settings Gait, in particular, has been assessed by combining data from an onboard sensor system, ethnographic observations and self-confrontation interviews. We discuss the results of this study with respect to the so-called activity analysis framework which is considered both as a resource for the design of new technologies and as a technology of design in the healthcare domain. In particular, we consider the potential for innovations regarding here, with the integration of onboard sensors, 1) the design of training 2) the design of artefact and work formats 3) the design of new mechanisms for health knowledge generation and validation.

Key words: ergonomics, conception, technology, health, activity analysis, gait

Short title: Ecological design of healthcare technology - ECOTECH 
1. Brain Spine Institute, University of Paris 6 /INSERM UMR 1127 CNRS UMR7225, 75013, Paris, France. Elodie.lalo@univ-orleans.fr, marie-laure.welter@psl.aphp.fr, ross.parry@icminstitute.org

2. Laboratoire PRISME, Université d'Orléans, Château de la Source, Avenue du Parc Floral BP 6749, 45067 Orléans Cedex 2. meryem.jabloun@univ-orleans.fr, julien.roussel@univorleans.fr, olivier.buttelli@univ-orleans.fr.

3. Université d'Orléans, Allée du Château, BP 6237, 45062 Orléans Cedex 2. jacques.riff@univ-orleans.fr

4. Assistance Publique-Hôpitaux de Paris, Groupe Hospitalier Pitié-Salpêtrière, 47 boulevard de l'Hôpital, 75013 Paris, France,

5. Department of Neurology, Chang Gung Memorial Hospital and University. No. 5, Fusing Street, Gueishan Hsien, Taoyuan City, Taiwan.neurozoe@gmail.com

Corresponding author: elodie.lalo@univ-orleans.fr

Université d'Orléans, Château de la Source, Avenue du Parc Floral

BP 6749, 45067 Orléans Cedex 2

Tél: +33 (0)2 38417171 


\section{Introduction}

Technological innovations have progressed considerably in response to the needs of people in vulnerable or at-risk situations, such as elderly populations. Such technology has served to i) maintain independence through progress in rehabilitation tools, intelligent housing, alarms, adaptive aids and communication technology; ii) contribute to health through the development of biomedical devices, surgical implants (e.g. neurostimulation), computerised medical imaging techniques, biomedical engineering applied to bodily tissue (regeneration), or onboard systems for monitoring vital signs (see [1] for a review of such projects based in France). The development, integration and application of onboard sensor technology is central to the ECOTECH project which focuses on personalised medicine.

Specifically, it aims to characterise gait disturbances in ecological settings and to detect and overcome risk situations for patients with Parkinson's disease by 1) designing new clinical evaluation methods and tools to identify patient difficulties when walking and provide accurate measures of patient response to treatment and 2) informing the planning of other interventions from therapeutic education, with the use of compensatory strategies, to environmental adaptation. This project benefits from a French-Taiwan partnership with a SME specializing in ergonomic sensor equipment. It incorporates research groups specializing in neurology/neuroscience and movement disorders, technology and physiology as well as ergonomics.

The conditions for successful innovation and implementation (defined as the "process of integrating a new technology into established workflows") are not bounded to technological progress or societal processes (see for instance [2]). In the present article, we consider the so-called approach of activity analysis [3] [4] as a vital resource in the design of new health 
and well-being technologies. The results of this study have been obtained through the analysis of the activity of PD patients in daily life situations. As such, the social, cultural, material and technical circumstances for any given activity are patently unique (Theureau, 1992; 2010). It provides for particularly rich and complex data which, by its very nature, enables a contextualised account of that activity:

- daily life events for PD patients occur in social settings which strongly determine the individual's course of action. Age, health personal circumstances (single, married, separated, widowed, living with family) and competing commitments of people within a patient's support network are defining elements of a patient's situation;

- the cultural and historical dimensions are manifest in the activity of a patient through the person's relationship to their health and disease as well as their rapport with healthcare services;

- material and technical constraints equally structure the person's activity in terms of financial resources, technical aides, modified or adapted living environments and physical access to places which the person frequents;

Activity, such as it is conceived in this study is a global dynamic integrating:

- modalities of actions implicating motor abilities and whole corporality. Gait and mobility are considered in the wider scope of daily activities (locomotion is rarely an objective in itself);

- a cognitive and perceptive dimension implicating decision making, preoccupations, capacity for anticipation, focus upon attentional modalities (e.g. symptoms, fatigue), anticipation of difficulties in locomotion, fixation upon certain symptoms; 
- the way in which people generating understanding (i.e. learning through one's own experience) through metacognitive processes and practical knowhow;

- affective states or affective dynamics through the course of the activity. This may imply concerns, fear, satisfaction, surprise, relief, frustration, shame, disappointment, anger, pleasure or hope. Emotional states may be of varying spectra, complexity or stability (not every patient studied presented with the same combination of emotions). Emotional dynamics are experienced with varying levels of intensity. Emotional valence may be hardy perceptible, a background to the experience-or at the other extreme, particularly intense, dominating the way in which an event is experienced. The duration of such dynamics are also a subject of interest.

Typically, healthcare research involves the development of experimental protocols using neuroimaging or biomechanical markers or participant observation of hospital activities [5] [6]. Going beyond the traditional distinctions of disciplines, we present here a part of the results in order to discuss the potential of these processes based upon activity analysis as a resource for the design of new technology and as technology per se in design.

\section{Material and method}

\subsection{Ecological study}

Our objective is to study the "situated action" [7] of patients with Parkinson's disease in the particular circumstances (social, cultural, material and technical contexts) in which acting invariably occur. One aspect of this work has involved ethnographic observation of patient and clinical staff activities including: 
- thirty clinical consultations for the purposes of examining patient-doctor interactions through the course of Parkinson's disease management.;

- six UPDRS (Unified Parkinson Disease Rating Scale) evaluations to review clinical processes and functional evaluation techniques;

- three medical team meetings pertaining to patient selection for surgical intervention (deep brain stimulation);

- Eight hours of observations (over two separate sessions) for each of 8 patients with Parkinson's disease in their natural setting-within the home and in the wider community. Particular interest was invested in those circumstances likely to provoke gait disturbances.

\subsection{Integrated approach}

Using a holistic approach, ethnographic observations (supported by audiovisual recordings) of patients in their daily life routine (see last point of 2.1 ) have been coupled with data obtained from onboard sensors. This process was followed by the completion of selfconfrontation interviews in order to understand the patient's subjective experience of the activity in question.

Thanks to a cooperation between French and Taiwanese groups [8], gait and locomotor disturbances were monitored during unconstrained activity using a system of wearable sensors (see fig.1). For the purposes of the present paper, only data recorded from one accelerometer, inertial motion units and surface electromyography (sEMG) sensors fixed to the lower limbs are presented.

[Insert figure 1 about here] 
All data obtained from onboard sensors has been synchronized with video data using CAPTIV software (TEA).

Self-confrontation interviews (approx. 2 hours) were conducted after each recording. This involves obtaining a first person accounts of particular sequences of the patient's activity [9] so as to document the patient's experience. It involves presenting the recordings of the patient activity to the patient themselves and proposing questions regarding their activity in terms of emotion, sensation, preoccupation, interpretation, communication and actions during the recording periods of activity, and in particular motor events (loss of balance, freezing of gait, etc.).

\section{3 sEMG data processing}

sEMG data are of great interest for studying neural drive modifications during motor activity [10]. However, sEMG signals are highly nonstationary with neither wide nor narrow band spectra, especially under dynamic recording conditions [10], [11]. Signal processing techniques capable of dealing with the SEMG features are required. The method proposed in the present study first decomposes the SEMG signal using the Empirical Mode decomposition (EMD). Introduced by N. Huang [12], the EMD is a data-driven decomposition that suits to nonlinear and non-stationary signals. It provides intrinsic oscillatory modes, the called Intrinsic Mode Function (IMF). These IMF reflect phenomena occurring on several time scales.

We then calculated the complexity of each IMF by means of the Lempel-Ziv complexity measure [13]. This measure actually helps in revealing the regularity and randomness of the considered signal [14]. By combining the EMD and the Lempel-ziv measure in this way, we aim at characterizing the degree of organization of SEMG IMFs for healthy and PD subjects. 
In the following, the proposed method was applied on SEMG signals recorded on a patient with Parkinson's disease and on a healthy adult subject for comparison. SEMG was recorded continuously during daily routine by means of surface electrodes located on the soleus muscle (ankle plantar flexor). Current processing was applied during selected gait sequences. Each value was computed from three consecutives SEMG bursts which represented 3 gait cycles.

\section{Results and discussion}

In this section, we present a series of results obtained through the course of the ECOTECH project and their relation with a target of a technological program [15] which distinguishes itself by the practice of particular design having for objective the development of the activity of the people concerned: doctors, health professionals, people with PD and their close circle.

Three particular themes will be considered: 1) the design of tools for training and development, 2) the design of tools for assisting in the interactions between patients/carers and in the work of multidisciplinary medical teams, 3) the design of new mechanisms of health knowledge generation and validation.

\subsection{Designing educational programs: enrichment of training for healthcare professionals} and therapeutic education for patients

The results of this study enable us to identify the knowledge and knowhow of patients evidenced through the way they manage their daily life activities.

Numerous strategies were employed by patients through the course of their daily life activity in order to deal with the requirements of the activities that they engage in and the constraints imposed by their disease. 
For example, PD patients were observed to use various avoidance strategies during their daily life activity. In such cases, the patient, having identified similar elements from another previously lived situation, modified a movement pattern so as to avoid loss of balance, falling or personal injury. This included particular postures to prevent, avoid or reduce the impact of certain negative clinical phenomena related to balance and locomotion. Some patterns were used to improve gait control, such as the 'military march' evoked by a patient when walking through a busy street. She reported that this type of walking with a marked heel strike (taught to her by a physical therapist) gave her a better feeling and rhythm in her stride, thus enabling her to manage walking in a complicated situation. In order to avoid freezing upon the initiation of gait (start hesitation), some patients were observed to use intentional weight shifting (both laterally and backwards) or at other times sought to exaggerate components of the movement (i.e. step length, foot clearance, knee flexion). Below are some of the experiences described by patients:

“I'm fortunate in that I can run quite well even when I'm OFF. In fact I find that if I'm having trouble walking, I can often straighten it out by getting a bit of a jog up." [Patient]

"I frequently walk up on my toes. Because when I'm stuck, it's a good way to get moving again. When I go to the hospital, they call me the dancer." [Patient]

"When I'm close to a chair or in a difficult situation, I concentrate and make a big step to get started." [Patient]

"Sometimes I walk with more support on my heels. Or not really my heels but with my body slightly behind. With my centre of gravity shifted backwards". [Patient] 
"But I walk quickly, I up the tempo. I know that when I walk quickly, I feel more stable than when I walk slowly. It helps me to avoid falling." [Patient]

"If I'm in the kitchen with a class in the hand, I would often have a fear of spilling what I'm carrying because of a fear of falling. In order to avoid falls, I often ease myself onto my knees in order to avoid a real fall." [Patient]

The use of comfort strategies, when a patient choses a particular posture to reduce pain or discomfort, was also observed. For example, one patient reported used what she called a 'duck walk' pattern to reduce pain in the lumbar region while walking when OFF. By increasing the external rotation from the hip when walking, this patient found she could relieve this 'bar in her back'. In another case, a patient was observed to shift her weight from one leg to another. She reported that this type of 'shimmy' helped to reduce back pain associated with static standing postures.

Based upon these observations, one might envisage content for training to improve the practice of health professionals and to improve the content of therapeutic education. The enrichment of the training of clinicians stems from the knowledge of how patients appropriate strategies and complements their diagnostic activity and counselling of patients. The therapeutic education for patients and their carers can be categorised into several components: 1) develop ability to recognize categories of actions from their own behavioural repertoires; this requires an ability for the subject him/herself or the carers to recognise the constructive value of this experience [16], (2) help to overcome gait difficulties by becoming aware, understanding and experimenting with these kinds of strategies [17] (3) organising the sharing of experiences, made through exchanges, mutual knowledge sharing 
between patients and professionals but also within groups or communities of patients, which we will further discuss in part 3.3.

The work of generating content for training based upon ergonomic analysis of activity is a product of design technology used with success in the training of people learning to ride motorcycles [18]; the conservation of expertise, knowledge and knowhow in industry [19]; adult training programs [20]; and the management of fatigue for deep sea fishermen [21]. The analysis enables an update of thematic, an integral part of the activity and often forgotten, underestimated or absent in the curriculum or current practices.

\subsection{Designing artefacts, tools and working/meeting configurations for medical staff}

Another possibility for design is based upon the results of the activity analysis of healthcare professionals involved in the care of patients: tests, diagnostics, patient follow-up, determining effective treatment, medical decision making. The inherent temporal dilemma in patient assessment can be characterized by a small window of time for evaluation of the patient status versus a need to establish understanding of patient symptoms and disease evolution over long periods of time.

The design, in this case involves the development of new artefacts. Cognitive artefacts may be defined as "those artificial devices that maintain, display, or operate upon information in order to serve a representational function and that affect human cognitive performance." [22]. Cognitive artefacts are words, man-made things that seem to aid or enhance cognitive abilities. 


\subsubsection{Designing artefacts to support interactions with patient and self-reports}

Our observations confirm that the interactions between patients and medical teams pose certain difficulties [23] [24] particularly given that a large part of the daily life situations which the patient faces are considerably different in nature from the conditions under which clinical evaluation, diagnostics and rehabilitation programs are typically conducted. This problem is evidenced in the following extracts:

"Even though I tell my doctor how things are at home, on the day that I go to the hospital, just by chance I'm in the form of my life! I call that the teacher's pet effect-." [Patient]

"When I go to the hospital, they make me walk in the corridor. But there I don't shuffle and I don't freeze-there's no obstacle or corners, so for me it's no problem." [Patient]

"In any case, I think the problem is that to understand what happens, the doctors need to see me in-situ, over a certain period of time." [Patient]

Relying exclusively upon patient self-reports may also risk the possibility of a misunderstanding. For example, patients were observed to have difficulty when describing the effects that medication had upon their symptoms or understanding gait specific terms such as 'freezing' (sensation that the feet are glued to the ground). In addition to this, there may be many reasons for which the patient's perception and the clinican's assessment of locomotor performance are seldom the same.See also examples bellow:

"He's independent in activities of daily living. But... I'm not sure how he actually manages with work. With him I'm never sure if he's really telling me how things are." [Neurologist] 
"Sometimes I tell myself, 'the doctor already does so much for me, I shouldn't trouble him with that detail'. But I guess that not being able to walk properly is a pretty big detail." [Patient]

In the case of Parkinson's disease, a key element is the ability to adjust therapy according to motor fluctuations through the course of a day, particularly with respect to oral medications.

This type of fluctuation is considered here in terms of the organisation of muscular activity. Figure 2 illustrates this using examples from the soleus muscle (ankle plantar flexor) of a PD patient and a healthy adult control subject during unconstrained walking. As can be seen, fluctuations in the complexity of this signal are of relatively greater amplitude in the PD patient over a similar window of time. This measure of complexity has been based upon the Lempel-Ziv quantification. It provides an account of the deterministic behaviour of the observed signal. A value of complexity tending towards 0 would indicate a 'rigid' organisation while values closer to 1 would indicate a more random behaviour. In our example (fig.2 upper panel), at the time of the medication, the complexity of the patient's sEMG activity is comparable to that of a healthy adult subject (value around 0.5 ). After this time, this value decreases below 0.4 , indicating that the organisation is less complex. The reduction in the complexity would reflect a diminished capacity for adaptation with the onset of a more stereotypical activation.

It would also seem that patients have a keen sense of these ON/OFF fluctuations (with or without the effects of medication) which they express during the interviews.

"Two hours or so after the medication I start to feel it. First in my hand. It's like pins and needles, like the hand starts to go to sleep." 
"I know there are going to be problems with walking. When I put my foot down, it's like I'm walking on unsteady ground. We're not expecting it to be like that. It's like I'm in an old house and I step on an unsteady floorboard. Like a floorboard that is rotting away. You don't fall through but you feel something unstable underneath you. It's just not very solid. It's like a sense that I lose some steadiness in the ground and I feel that. And it shoots up to my head."

Obtaining verbal accounts from patients is thus a central part of responding to a problem which reveals itself a major issue. It is interesting to note that the use of elicitation interviews have proved effective in anticipating seizure events as a complement to electroencephalographic techniques [25].

[Insert figure 2 about here]

In order to document motor fluctuations, medical staff must rely upon interviews with patients:

"The descriptions that we obtain need to be categorized quickly so as to extract the relevant information. We search the minimal amount of information over a given timescale to evaluate the effects of medications in terms of their temporal dynamics and their impact be it positive or negative. We work rather on the resolution of the problem." [Neurologist]

We have been able to observe medical staff using different modalities for soliciting patients, sometimes with the use of personal tools designed to support patient interaction. For example, one intern sketched a representation [26] of a patient's reported daily motor fluctuations with respect to the medication regime into the medical chart (see fig.3). Despite the interest of this illustration, the use of these kinds of supports remains relatively limited. 
Its use is not shared between caregivers and is not developed further into a more formal tool to orient patient care. Nonetheless, these types of artefacts are potentially valuable foundations in the type of patient-oriented design which we propose. Taking stock of existing artefacts used by carers in collaborative work, identifying concrete possibilities for their different modes of use, fostering the testing and appropriation of their use, and developing new tools through a shared, iterative, process-one that is focussed upon the actual activity and work demands of the carers/actors involved.

[Insert figure 3 about here]

\subsubsection{Designing artifacts to help collective decision making for neurosurgery} selection

Deep brain stimulation (DBS) is a neurosurgical procedure involving the implantation of a neurostimulator which sends impulses into the brain via electrodes located in the designated structure. In the specialist movement disorder service observed, this decision was undertaken by a specialized multidisciplinary team (MDT). Selection of appropriate PD candidates through a methodical interdisciplinary screening is considered a prerequisite for a successful surgical outcome [27]. The results of studying the MDT meeting in real context provide information on:

- how the multidisciplinary team manage this decision making process hinging on the complexity of the human nervous system and the heterogeneity of each clinical case;

- which collaborative processes are implemented during the meeting and how the coordination between professionals operate. 
We payed particularly attention to the potential emergence from the investigation of a reliable structure of the MDT meeting. Our study highlights the relative specificity of the DBS decision making process and the need to recognize patient selection as a complex problem solving exercise. In particular, two distinct processes were observed to characterise the collaborative work of the multidisciplinary team. The first involved a systematic analysis of clinical data to identify known contraindications for the DBS procedure. The second involved a broader modelling of the patient situation, taking into account the individual's personal situation and mobilising more implicit knowledge and clinical experience in order to determine the individual risk-benefit scenarios associated with the proposed surgery.(see fig.4).

[Insert figure 4 about here]

Within the ECOTECH project, this collaborative decision making process formalisation has been requested by another neurological team specialised in DBS so as to assist and improve their own practices. Similar to other work carried out in multidisciplinary teams in oncology [28], these results and the modelling of the decision making process improves the actors understanding of their own work: it supports their ability to generate meaning and interpret complex activity.

\subsection{Designing new crowdsourcing mechanisms for parkinsonian health knowledge generation and innovation}

Our results highlight that the analysis of activity in real life situations integrating the contribution of healthcare professionals (part 3.2) but also that of patient's (part 3.1) through the description of their experience allow for the production of a body of original work. We have, for example, improved knowledge regarding freezing events by identifying 
distinct types (e.g. "glued to the ground" or "small accelerated steps"). Interestingly, the phenomenological data assisted in distinguishing the different sensations unique to two particular types of freezing of gait. (see fig. 5).

\section{[Insert figure 5 about here]}

This knowledge, produced in the framework of an in-depth study of a handful of cases, shows how the enrichment and validation of knowledge in healthcare may be generated through innovative research methods, quite distinct from the more traditional means mobilised in many scientific studies. In the context of increased accessibility to means of communication (internet, social networks) and the associated progress of these tools is that of "Crowdsourcing" [29] which offers the possibility to support the creativity, intelligence, the knowledge and knowhow of a large number of people, beyond that which is traditionally possible. Crowdsourced health studies and quantified self-experimentation projects are emerging as a complement to traditional mechanisms of health knowledge generation. Participants are crowdsourced via meetup groups or the Internet, i.e., recruited in vast open calls using social media and other techniques allowing individuals to self-select participation: "Integrating self-tracking device data and crowdsourced health experimentation results into personal electronic health records for an overall picture of preventive health is an important medical challenge" [30]. This "citizen science" in a digital world may lead to new paradigms of health where not only the knowledge discovery process but also the design process of an innovation is the result of complementary skills and expertise of talented "but functionally divided groups of persons" (i.e. patients, clinicians, data managers).

In our case, it is not only the "big data" or the tracking devices which is the target. But understanding the individual experiences to explore, experiment, exchange and validate. 
The technological challenge here is to design interdisciplinary and interindivual collaborations to solve new problems and improve solutions.

\section{Conclusion}

The ECOTECH project, in the framework of an interdisciplinary approach, has been conceived in order to develop new tools and new technologies in health, in particular for Parkinson's disease. In this article, we have attempted to show and illustrate the interest of a particular design technology which has three principal characteristics: 1) it is based upon the rigorous analysis of real situations in daily life activity and in hospitals, 2) a considerable interest is invested in the experience of patients and their ability to report their experience as a vital source in the production of scientific knowledge, 3) it proposes mechanisms for the generation / validation of new knowledge and innovative design based upon collaborative work between researchers, healthcare professionals and patients themselves.

This high stakes alternative falls into the current wave of personalized medicine, citizen science and crowdsourcing.

\section{Acknowledgments}

The present work is embedded in a French national project ECOTECH (www.echotechsan.org) and it is supported by the French National Agency for research under the contract No. ANR-12-TECS-0020. 


\section{References}

1. Cornet G, Carre M. Technologies pour le soin, l'autonomie et le lien social des personnes âgées : quoi de neuf ? Gérontologie et société 2008;3:113-128.

2. Thuemmler C, Lim A, Holanecd I, Fricker S. A methodology to assess social technological alignment in the health domain IRBM, 2016 (In Press).

3. Theureau J. Dynamic, living, social and cultural complex systems: principles of designoriented analysis. Revue d'intelligence artificielle, 2002;16:485-516.

4. Theureau J. Course-of-action analysis and course-of-action centered design. In Hollnager E editor. Handbook of cognitive task design; 2003 p. 55-81.

5. Vega A. une ethnologue à l'hôpital. L'ambiguïté du quotidien infirmier. Paris, Editions des archives contemporaines 2000.

6. Peneff J. I’hôpital en urgence. Etude par observation participante. Edition Métailié 1992.

7. Suchman LA. Plans and situated actions: the problem of human-machine communication. Cambridge University press 1987.

8. Buttelli O, Parry R, Jabloun M, Ravier Ph, Ma HP, Ferveur N, Lalo E. "Methodological considerations about motor activity tracking in real life settings", in Advances in Science, Technology, Higher Education and Society in the Conceptual Age: STHESCA Edited By Tadeusz Marek Published by AHFE Conference 2014.

9. Theureau J. L'entretien d'autoconfrontation comme composante d'un programme de recherche empirique et technologique. Lehenaff $D$, Mathieu $C$. éditeurs. Actes des llème Journées internationales des Sciences du Sport 2002.

10. Bercier S, Halin R, Ravier P, Kahn JF, Jouanin JC, Lecoq AM, Buttelli O. The vastus lateralis neuromuscular activity during all-out cycling exercise. J Electromyogr Kinesiol, 2009;19:922-930. 
11. Min L, Zhizhong W, Zhengjin F. Detecting nonlinearity of action surface EMG signal. Physics Letters A 2001;290:297-303.

12. Mandic DP, Rehman NU and Wu Z, Huang NE. Empirical mode decomposition-based timefrequency analysis of multivariate signals: the power of adaptive data analysis. IEEE Signal Processing Magazine, 2013;30:74-86.

13. Lempel A, Ziv J. On the complexity of finite sequence. IEEE Transactions on Information Theory 1976;22: 75-81

14. Zozor S, Ravier P, Buttelli O. On Lempel-Ziv complexity for multidimensional data analysis. Physica A 2005;345:285-302.

15. Durand M. Un programme de recherche technologique en formation des adultes. Une approche enactive de l'activité humaine et l'accompagnement de son apprentissage/développement, Rennes: PUF ; 2008

16. Bourgeois E, Albarello L, Barbier JM, Durand M. Expérience, activité et apprentissage. Contribution. In: Albarello L, Barbier JM, Bourgeois E, editors. Expérience, activité, apprentissage, Paris: PUF; 2013, p. 1-11.

17. Bourgeois E. Expérience et apprentissage, la contribution de John Dewey. In: Albarello L, Barbier JM, Bourgeois E, editors. Expérience, activité, apprentissage, Paris: PUF; 2013, p. 13-38.

18. Aupetit S, Espié S. Analyse ergonomique de l'activité de conduite moto lors de la pratique de l'inter-files région parisienne. Activités 2012;9:48-70.

19. Brunet M, Riff J, Thieffinne C. L'innovation par la préservation des savoir-faire. Un enjeu pour l'ergonomie dans une entreprise aéronautique. $47^{\text {ème }}$ Congrès de la Société d'Ergonomie de Langue Française. 5-7 septembre, Lyon, 2012, p. 14-17 
20. Durant M, Saint-Georges I, Meuwly Bonte M. Le curriculum en formation des adultes : argumentation pour une approche « orientée activité ». Raison éducative 2006:185-202

21. Sennegon B, Grison B, Ravier Ph, Buttelli O. Activity analysis aboard dredgers: an exploratory methodology combining psychological and physiological data. Activités 2012;9: 112-132.

22. Norman A. "Cognitive artifacts" In Designing interaction, New York: Cambridge University Press; 1991, p. 17-38.

23. Falzon P. Dialogues fonctionnels et activité collective. Le travail humain 1994;57:299-312

24. Cicourel AV. Le raisonnement médical. Une approche socio-cognitive. Seuil, Collection Liber, Paris 2002.

25. Petitmengin C, Navarro V, Van ML. Anticipating seizure: Pre-reflective experience at the center of neuro-phenomenology. Consciousness and cognition 2007;16:746-764.

26. Larkin JH, Simon HA. Why a Diagram is (Sometimes) Worth Ten Thousand Words. Cognitive Science 1987;11:65-100.

27. Shukla AW, Okun MS. Surgical treatment of Parkinson's disease: patients, targets, devices, and approaches. Neurotherapeutics 2014;11:47-59.

28. Falzon P. Computer support for multidisciplinary work in cancerology: decision-making and the building of expertise. In F. Darses F, Zaraté P editors. Third International Conference on the design of Cooperative Systems, 1998, Cannes, France.

29. Torr-Brown, S. (2013) Crowdsourcing for Science and Medicine: Progress and Challenges The Journal of OncoPathology. 2013;1:75-81.

30. Swan, M. Health 2050: The Realization of Personalized Medicine through Crowdsourcing, the Quantified Self, and the Participatory Biocitizen. JPM 2012;2:93-118. 
Figure 1: ECOTECH device and data collection example: coupling of biomechanical and physiological sensors with audio-visual recordings. Panel A presents two different types of onboard sensors (sEMG and inertial motion unit) and the type of action camera used for the purposes of observations. After the recording, the different datasets are synchronised (Captiv software, TEA), as illustrated in panel B.

Figure 2. Lempel-Ziv complexity of the $1^{\text {st }} \mathrm{IMF}$ component from the right soleus SEMG: recording has been performed during gait activity in daily life routine in a patients with Parkinson disease (upper panel) and in a healthy participant (lower panel). Scale complexity goes from 0 to 1.

Figure 3: Reconstruction of a schema representing patient's motor fluctuations according to their daily medication regime. Periods where the patient experiences parkinsonian symptoms (tremor/akinesia) are shown in the filled bars while periods where the patient experiences abnormal movements secondary to the medication (dyskinesia) are represented by the striped bars. The traced line represents time where the patient is asymptomatic. The different triangles represent different types of medication taken throughout the day. This figure is a copy of the original handmade sketch. It was copied into a patient's medical chart by an intern of the neurological service.

Figure 4: Two distinct reasoning processes observed to be used by the multidisciplinary medical team when determining if patients with Parkinson's disease were suitable for neurosurgical intervention. 
Figure 5: Different types of freezing of gait observed in patient activity: panel A presents the "glued to the ground" freezing type while panel B presents the "small accelerated steps" freezing type. An example of a transition between two different types of freezing is presented in panel $\mathrm{C}$; i) the patient starts to walk, beginning with the left foot, ii) the forefoot of the left leg remains in contact with the ground. The patient explains that he 'does not feel his leg' and associated this sensation with that of a tremor. Repeated flexion of the left leg is observed during approximately 2 seconds; iii) the patient manages to place his left leg on the ground but explains that when he forces a steps, the leg begins to become more stiff, or tight; iv) the patient advances with small steps, he reported that he felt the calf muscle and thigh to be stiff or tight. A change in the knee range of motion and irregular muscular activity is observed, v) the patient comes to a halt. 
A

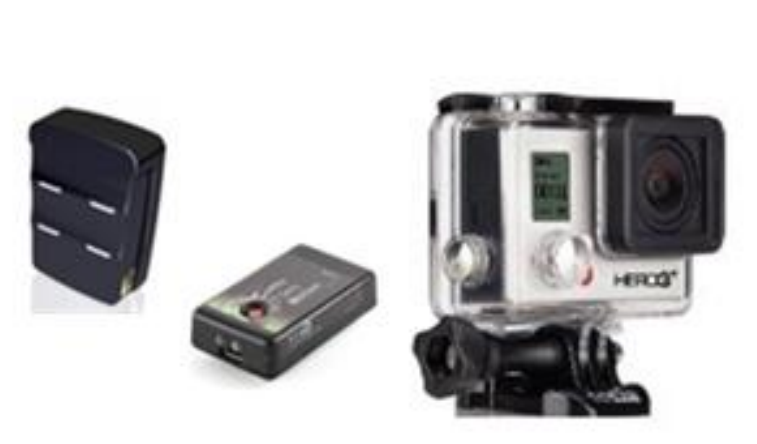

B

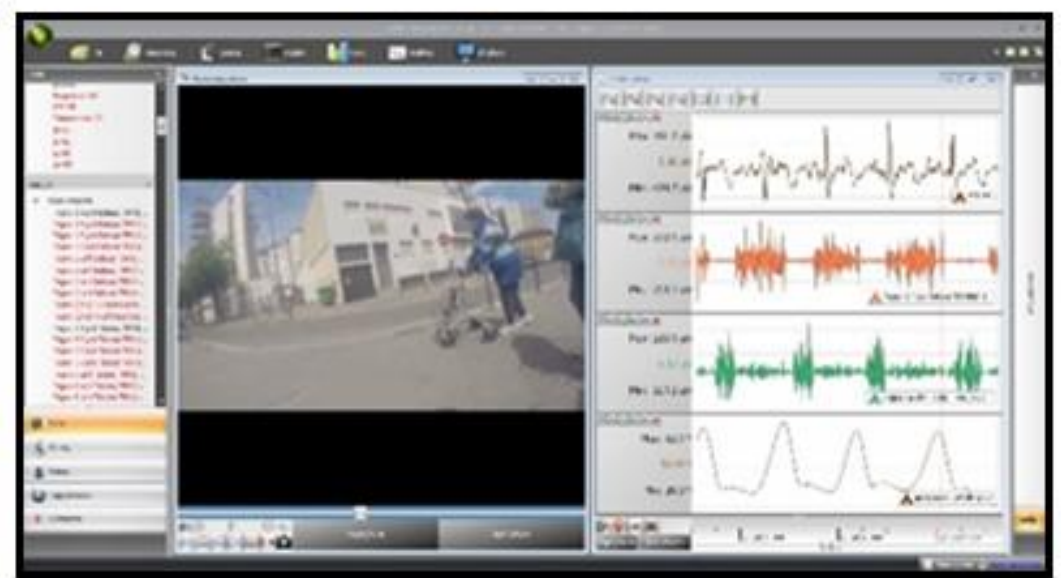

Figure 1 


\section{EMG Right Soleus}

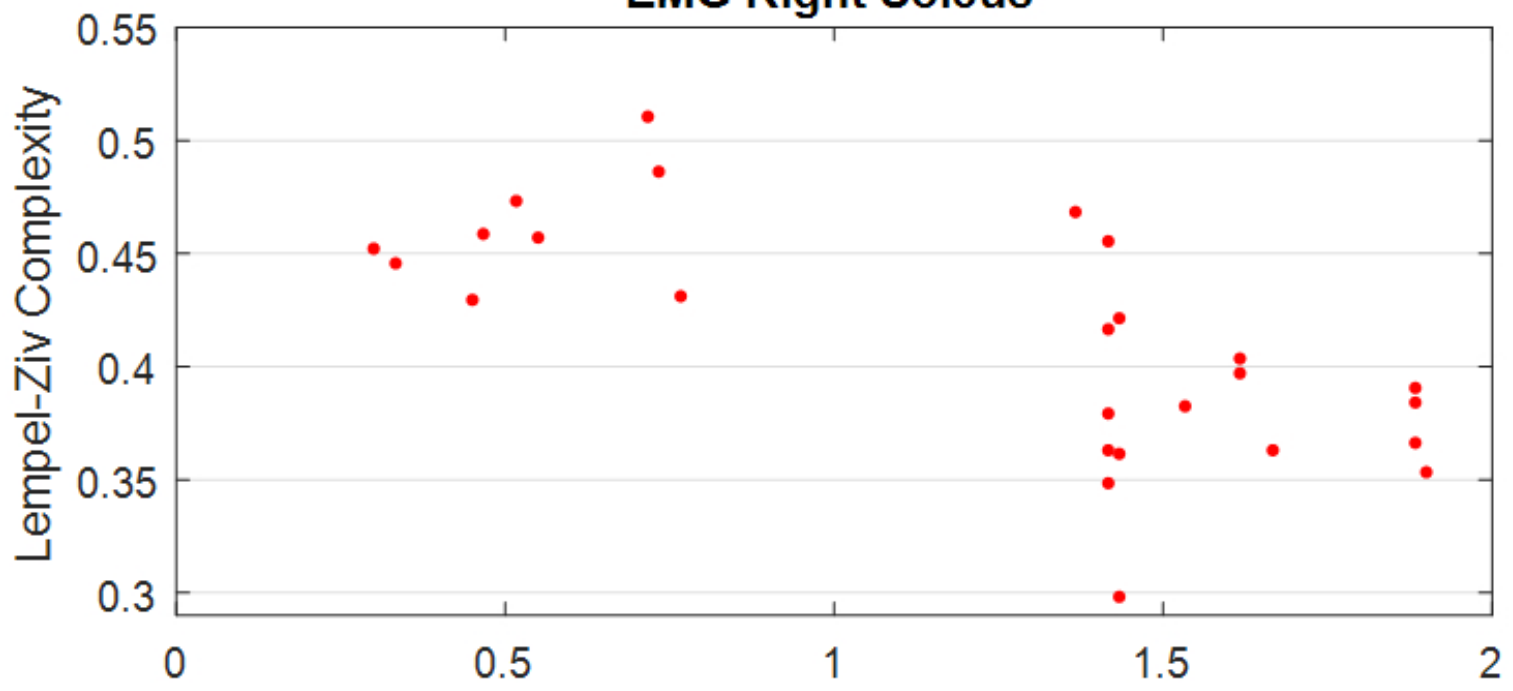

Delay from last medication $(\mathrm{h})$

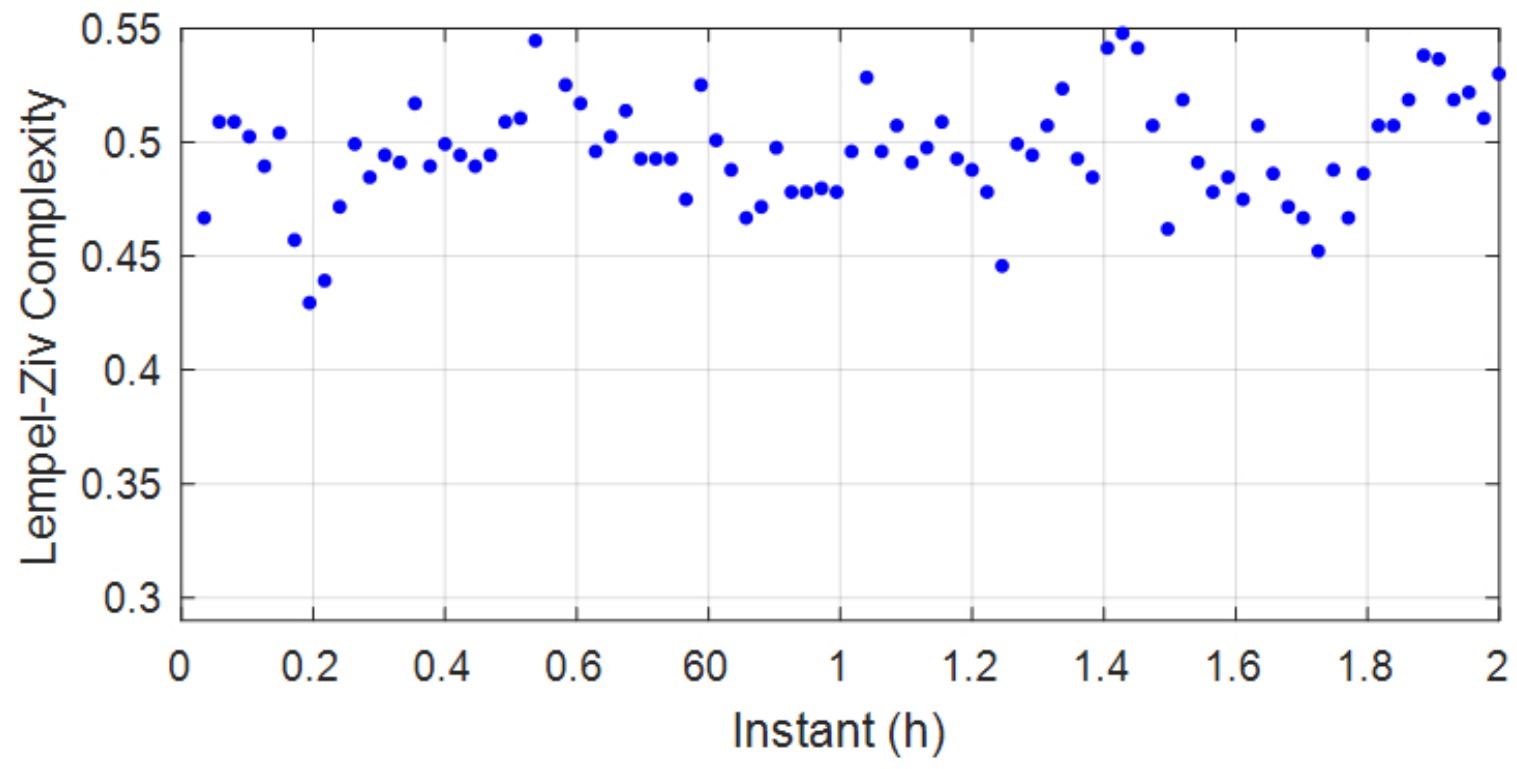

Figure 2 


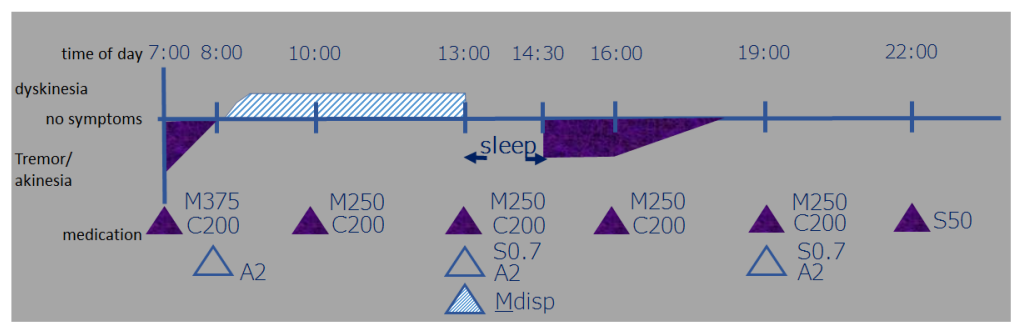

Figure 3 


\begin{tabular}{|c|c|c|}
\hline \multicolumn{3}{|c|}{ Active search for a contraindication } \\
\hline \multicolumn{3}{|c|}{$\begin{array}{l}\text { iopathic PD? } \begin{array}{l}\text { Are there generalsurgical } \\
\text { contraindications? }\end{array} \\
\text { Are there active psychiatric problems? }\end{array}$} \\
\hline $\begin{array}{l}\text { How well do symptoms } \\
\text { respond to treatment? }\end{array}$ & $\begin{array}{l}\text { How much postural instability is } \\
\text { observed? }\end{array}$ & \multirow{4}{*}{$\begin{array}{l}\text { Would the outcome be } \\
\text { acceptable to the patient? } \\
\text { - qualitative parameters } \\
\text { - complex interactive phenomena } \\
\text { - modulated by subjective self- } \\
\text { - cumort }\end{array}$} \\
\hline How severe are the cogni & $\begin{array}{ll} & \text { Will DBS have an overall } \\
\text { tive deficits? } & \text { effect on quality of life? }\end{array}$ & \\
\hline \multicolumn{2}{|c|}{ How disruptive is the disease to the patient's lifestyle? } & \\
\hline $\begin{array}{l}\text { What is the patient's } \\
\text { social situation? }\end{array}$ & $\begin{array}{l}\text { Would potential } \\
\text { complications outweigh } \\
\text { benefits DBS? }\end{array}$ & \\
\hline
\end{tabular}

Figure 4 


\section{Freezing of gait in Parkinson's disease}

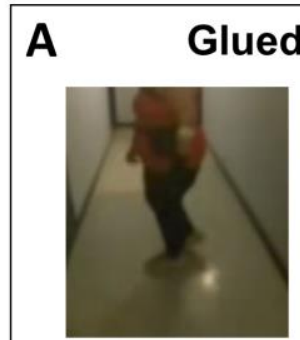

Forefoot remains on the ground 'Shaking' in the leg Heel rises / knee flexes

\section{B Small accelerated steps}
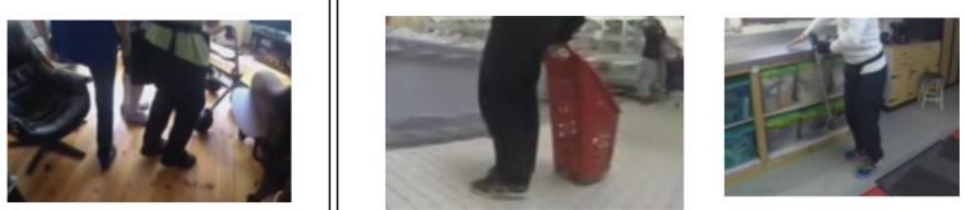

Both feet advance

Irregular speed

Limited foot clearance

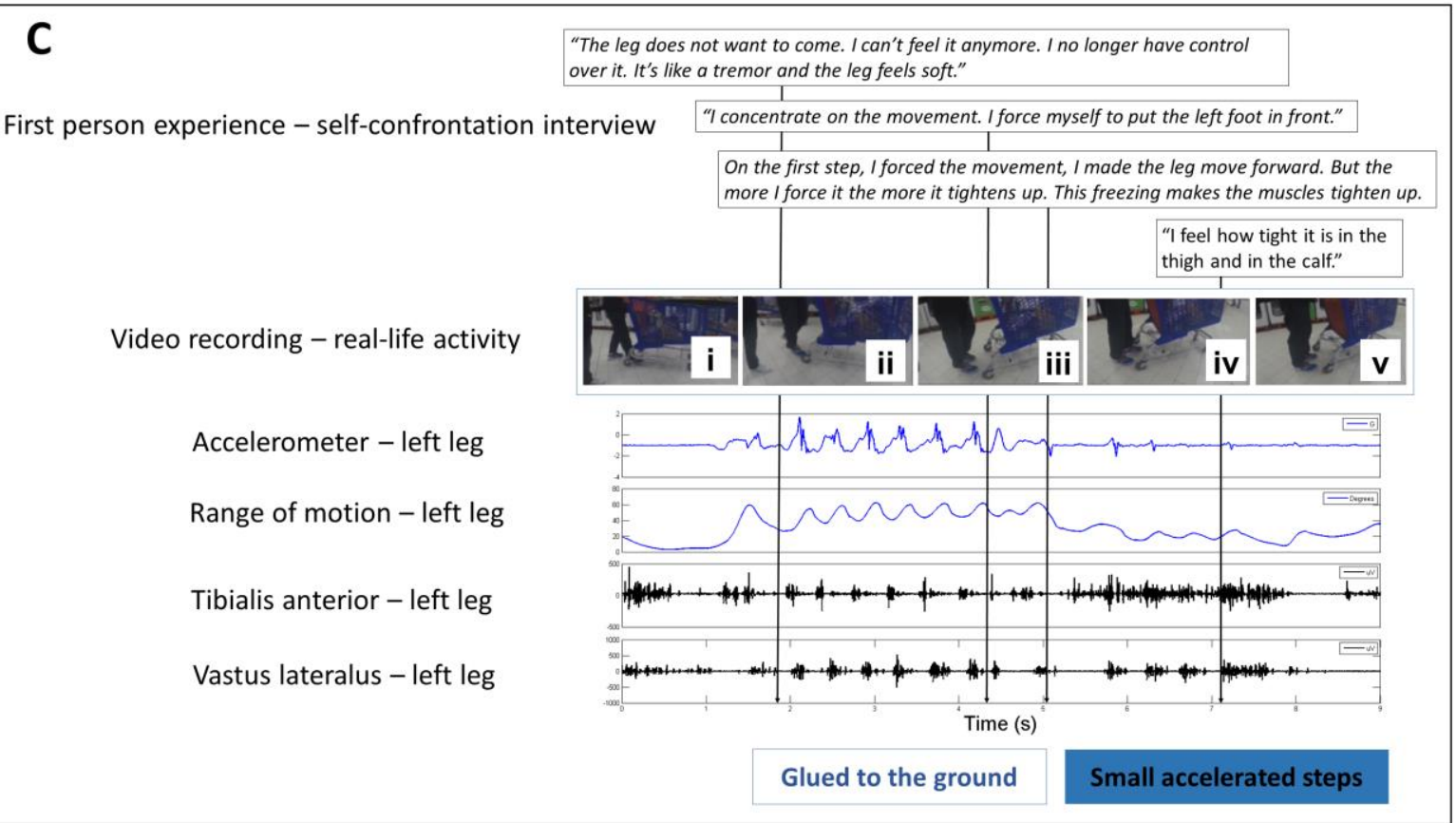

Figure 5 